\title{
Exigência nutricional de fósforo disponível para poedeiras comerciais após 63 semanas de idade
}
Almir Ferreira da Silva ${ }^{1}$, Carlos Bôa-Viagem Rabello ${ }^{2}$, Júlia da Silva Barros ${ }^{3}$, Rafael Santos de Aquino ${ }^{4}$, Edmilson Gomes da Silva ${ }^{5}$, Rodrigo da Silva Lima ${ }^{5}$, José Almir Ferreira Gomes ${ }^{5}$

\author{
${ }^{I}$ Zootecnista, Gerente de Produção da MULTICAMP LTDA. - CRMV-PE: 0554/Z - Av. Ayron Wellington de \\ Andrade - Lote 18- Quadra A. Distrito Industrial - Bezerros -PE. \\ ${ }^{2}$ Professor Adjunto - Universidade Federal Rural de Pernambuco. Av. Dom Manoel de Medeiros, s/n, Dois \\ Irmãos, Recife-PE. \\ ${ }^{3}$ Aluna de Graduação do curso de Zootecnia, Universidade Federal Rural de Pernambuco. Av. Dom Manoel \\ Medeiros, $s / n$, Dois Irmãos, Recife-PE. \\ ${ }^{4}$ Professor - Instituto Federal do Sertão Pernambucano (IF Sertão-PE) - Campus Ouricuri, Estrada do \\ Tamboril, s/n, Ouricuri-PE. 56.200-000. \\ ${ }^{5}$ Professores - Instituto Federal do Sertão Pernambucano (IF Sertão-PE), Campus Salgueiro, BR 232, $\mathrm{km} \mathrm{508,}$ \\ Zona Rural, s/n, Salgueiro-PE. CEP: 56.000-000. \\ *Autor para correspondência, E-mail: rodrigo.lima@ifsertao-pe.edu.br
}

\begin{abstract}
RESUMO. Por apresentar-se como terceiro nutriente mais caro das rações, o fósforo além de sua importância econômica, tornou-se objeto de estudo não apenas por estar relacionado com a taxa de crescimento, mas também, pelo seu envolvimento com desenvolvimento ósseo, produção e a qualidade dos ovos. Com isso, com o objetivo de demonstrar os níveis adequados de Fósforo disponível para galinhas poedeiras com 63 semanas de idade, realizou-se um estudo para avaliar os parâmetros de desempenho como peso dos ovos, massa de ovos, percentagem de postura, conversão alimentar, além das características de qualidade dos ovos tais como gravidade específica, peso da gema, peso do albúmen, peso da casca, percentagem da gema, percentagem de casca e percentagem do albúmen. No entanto, para que os índices de desempenho e qualidade dos ovos não sejam afetados em função de níveis de inadequados de fósforo disponível, recomenda-se a exigência de $0,30 \%$ e $032 \%$ respectivamente.
\end{abstract}

Palavras-chaves: Final de postura, mineral, ossos, postura, qualidade do ovo

\section{Nutritional requirement of available phosphorus for laying hens after 63 weeks of age}

\begin{abstract}
By presenting itself as the third most expensive nutrient rations, phosphorus addition to its economic importance has become an object not only be related to the growth rate, but also by its involvement in bone development, production and egg quality . Therefore, in order to demonstrate adequate levels of available phosphorus for laying hens with 63 weeks of age, we performed a study evaluating parameters such as egg weight, egg mass, laying percentage, feed conversion, to the gravity specific, yolk weight, albumen weight, shell weight, percentage of yolk, shell percentage and percentage of albumen. As well as percentage of ash, phosphorus and finally, the resistance to breakage of bones.
\end{abstract}

Key-words: End of egg laying, mineral, bones, laying, egg quality

\section{Introdução}

Nos últimos 30 anos, os grandes índices de produtividade alcançada nos sistemas de produção avícola, permitiu que o Brasil ocupasse lugar de destaque entre os países mais competitivos do mundo nesta atividade. Neste aspecto, os principais responsáveis por este desenvolvimento foram $\mathrm{o}$ acesso a novas 
tecnologias disponibilizadas no mercado, como também, toda estrutura consolidada no ponto de vista genético e gerencial.

Diferente da avicultura de corte, onde o Brasil com uma quantidade de 12 milhões de toneladas de carnes produzidas fechou o ano de 2013 como o terceiro maior produtor mundial neste segmento, segundo projeção da Companhia Nacional de Abastecimento (CONAB), a cadeia nacional produtiva de ovos ocupa apenas a sétima colocação na lista entre produtores mundiais, ficando atrás de países como China, Estados Unidos e Japão. De acordo com o Relatório anual da União Brasileira de Avicultura (UBA, 2013), o consumo de ovos no Brasil em 2012 foi de aproximadamente 160 unidades per capita por ano, quantidade baixa quando comparada com México, por exemplo, onde o consumo chega aproximadamente a 374 ovos per capita ao ano.

$\mathrm{O}$ ovo in natura destaca-se por ser o único alimento natural sem aditivos, que ao término de sua formação, encontra-se previamente embalado e pronto para o cozimento. Além disso, caracteriza-se por ser um alimento que apresenta um balanço quase completo de nutrientes essenciais para nutrição humana, contendo fontes nutricionais de excelente qualidade e com de baixo custo de aquisição.

Alguns minerais como o ferro, fósforo $\mathrm{e}$ magnésio, vitaminas e proteína de alta qualidade encontrada na albumina, são exemplos de nutrientes indispensáveis que constituem as propriedades químicas do ovo.

O aumento do consumo de ovos e a utilização de suas vantagens nutricionais pela população dependem da qualidade do produto oferecido ao consumidor, que é determinada por um conjunto de características que podem influenciar o seu grau de aceitabilidade no mercado (Barbosa et al., 2008).

Em relação aos fatores que incidem sobre os custos de produção do quilograma do ovo, a ração é o item que participa em maior proporção, perfazendo entre $65 \%$ a $70 \%$ do total dos custos. Diante disso, cada vez mais os nutricionistas desenvolvem dietas que propiciem um excelente desempenho produtivo. Por outro lado, é fundamental que estes profissionais avaliem constantemente os fatores que interferem diretamente na relação custo e benefício (Braga et al.,2005).
Depois da energia e da proteína, o fósforo $(\mathrm{P})$ é o nutriente mais caro nas rações para monogástricos, sendo objeto de estudo não apenas pela sua importância econômica e ambiental, mas por estar altamente relacionada com a taxa de crescimento e desenvolvimento ósseo, produção e a qualidade dos ovos.

$\mathrm{O}$ fósforo é um elemento que requer atenção especial na sua suplementação, pois quando administrado em excesso pode prejudicar a integridade das aves, reduzir a disponibilidade de cátions bivalentes e a hidrólise do fitato (Ballam et al., 1984). Contudo, o aumento da deposição de dejetos sobre as águas promovem a poluição ambiental em função da grande proliferação de microrganismos patogênicos, podendo afetar tanto a saúde humana, quanto a dos animais.

Em função da reduzida oferta de $(\mathrm{P})$ dos ingredientes de origem vegetal, são utilizadas como fonte suplementar nas dietas das aves, a fonte padrão de fósforo inorgânica e orgânica provenientes do fosfato bicálcico, ou farinhas de carne e ossos respectivamente $\mathrm{Wu}$ et al. (2006).

As exigências nutricionais de fósforo das aves podem ser afetadas pela linhagem, pela idade e pelo potencial genético (Singh, 2008). Segundo Faria et al. (2000), ao estudarem a influência da idades de poedeiras Hy Line - W36 sobre o desempenho e qualidade interna e externa dos ovos, observaram que aves mais velhas apresentam valores inferiores de produção e conversão alimentar, porém com maior peso dos ovos quando comparados com aves mais jovens. De acordo com Lesson \& Summers (2001); Silva et al. (2008), as recomendações dos níveis de fósforo disponível $(\mathrm{Pd})$ para poedeiras leves no período de postura, variam 0,15 até $0,50 \%$.

A partir destas observações, têm-se verificado que além dos mecanismos que influenciam a mobilização e deposição, os processos de absorção de ortofostatos em função da idade, não têm sido muito evidenciados por parte dos pesquisadores no momento de se estimar os valores de exigência nutricional.

Com isso, objetivou-se estimar o nível ideal de fósforo disponível para aves poedeiras que estejam em fase de pós pico de postura.

\section{Fósforo}

O fósforo foi descoberto e isolado ainda no ano de 1669 por Brand na Alemanha, porém, os primeiros registros de trabalhos realizados com 
este composto, surgiram por volta de 1809 na própria Alemanha, na França e, também na Inglaterra. Este elemento é caracterizado por ser um componente químico não-metálico, multivalente, de símbolo $\mathrm{P}$, número atômico $15 \mathrm{e}$ massa molecular de 30.975. Sua maior fração no organismo encontra-se em combinação com o oxigênio formando o ânion fosfato que, por sua vez, participa da constituição das membranas celulares, das fosfoproteínas, dos fosfolipídios e das moléculas de transferência de energia para as células na forma de ATP.

Na natureza, o fósforo pode ser encontrado nas jazidas minerais conhecida como Apatita (Butolo, 2002) cuja exploração tanto para fosfatos utilizados na alimentação animal, quanto para fertilizantes, torna-se de grande relevância para humanidade já que suas fontes são consideradas não renováveis.

$\mathrm{O}$ fósforo representa o segundo mineral mais abundante no organismo animal, com $80 \%$ do seu volume presente na matriz orgânica do osso em combinação com o cálcio na forma de hidroxiapatita, onde ambos são responsáveis pela rigidez das estruturas esqueléticas. Os 20\% restantes, estão presente nas hemácias, nos tecidos musculares e nervoso. Sua absorção ocorre no intestino delgado sob a forma de ortofosfato e a taxa com que é absorvido, depende de vários fatores reguladores como $\mathrm{pH}$ intestinal, nível de fósforo da dieta, relação cálcio:fósforo, vitamina $\mathrm{D}$ e outros minerais (Hays \& Swenson, 1988).

As diferenças quanto à disponibilidade biológica e coeficientes de digestibilidade do fósforo estão relacionadas principalmente com a sua origem, que pode ser tanto orgânica quanto inorgânica (Dias, 2006). De acordo Beterchini (2006) a disponibilidade encontrada no fósforo de origem vegetal depende do seu teor de ácido fítico, isto é, apenas $1 / 3$ do conteúdo total analisado destes ingredientes está na forma disponível para o metabolismo. Segundo Conte et al. (2002), a quantidade de fitato é muito variável entre as espécies vegetais, afetando diretamente a biodisponibilidade deste nutriente. Neste caso, Borges (1997) afirma que esta biodisponibilidade do $\mathrm{P}$ em ingredientes como o milho, farelo de trigo e do farelo de arroz, por exemplo, é de 33\%, $42 \%$ e $14 \%$ respectivamente.

\section{As funções do fósforo e sua importância}

O fósforo devido as suas inúmeras funções biológicas é considerado o mais versátil dos elementos minerais. Pois, constitui um componente essencial para a formação e manutenção das estruturas ósseas, atua no metabolismo celular através da síntese de ácidos nucléicos, auxilia na manutenção osmótica e balanço ácido básico. Participa na formação dos fosfolipídios e no metabolismo de aminoácidos, além de estar envolvido na transferência de energia para as células na forma de trifosfato de adenosina (ATP) e ativador de sistemas enzimáticos (Underwood, 1981).

O consumo inadequado de fósforo pode acarretar vários problemas, entre eles está a redução no tamanho e produção de ovos, elevação dos índices de mortalidade assim como, grau de mineralização óssea inadequada, caso esteja abaixo da exigência na dieta. Quando administrado em excesso, compromete a saúde das aves reduzindo a disponibilidade de cátions bivalentes e do fósforo fítico, promove a diminuição da hidrólise do fitato e um aumento da poluição ambiental, através das excretas que atingem ás águas dos rios, lagos e mananciais por meio da lixiviação do solo. A eliminação de fósforo pelas excretas ocorre principalmente devido a ingestão de fósforo não disponível nos alimentos, e o fornecimento de quantidades inadequadas desse mineral.

Algumas anormalidades em relação ao comportamento ingestivo dos animais podem ocorrer paralelamente quando são fornecidas dietas deficientes de fósforo, como por exemplo, a perda de apetite e o consumo de materiais indesejados como areia, madeiras e ossos. Este fenômeno é denominado de Osteofagia. Outras enfermidades como o Raquitismo e a Osteomalacia que são resultado de uma mineralização óssea inadequada em animais jovens e adultos respectivamente, também são proporcionadas pela carência de fósforo na alimentação.

Em galinhas poedeiras, a deficiência de fósforo atua diretamente sobre a produção e qualidade das cascas dos ovos, provocando redução nos índíces produtivos e alteração nos parâmetros de espessura de cascas e problemas na eclodibilidade. Estes efeitos são exercidos em menor proporção quando comparados à atividade do cálcio, pois a exigência nutricional de fósforo (P) é inferior, e seu percentual na composição dos ingredientes de origem vegetal é relativamente 
superior em relação aos íons de cálcio (Underwood, 1983). Segundo De Lange et al.(1999), o metabolismo do fósforo é afetado pela relação de Ca:P da dieta e, portanto, é fundamental que a proporção destes nutrientes estejam presentes em quantidades suficientes para o atendimento das exigências nutricionais das aves. Estes autores ainda reportam que, para a adequada formação da estrutura óssea durante a fase de crescimento, a concentração dos níveis de cálcio e fósforo nas dietas deve estar na proporção 2:1 respectivamente. Tanto o excesso de cálcio, quanto o de fósforo podem afetar respectivamente a disponibilidade de outros minerais e a qualidade da casca dos ovos (Silversides et al., 2006).

\section{Razão cálcio: fósforo e vitamina D}

O equilíbrio nutricional do cálcio e o fósforo no organismo não dependem apenas da maneira que estão incluídos nas dietas, mas fatores como a presença de vitamina $\mathrm{D}$ e a forma como estes nutrientes estão disponíveis para a hidrólise no metabolismo, são fundamentais para o bom desempenho das aves.

O cálcio após ser ionizado com moléculas orgânicas, realiza funções importantes como transmissão de impulsos nervosos, manutenção e contração muscular, ativação e estabilização de algumas enzimas e, também atuando como um elemento essencial na coagulação sanguínea.

O conhecimento dos níveis ideais de cálcio em cada fase do desenvolvimento da ave é de suma importância para ótimo desempenho zootécnico, pois o excesso de cálcio na dieta pode interferir na disponibilidade de outros minerais, como o fósforo, magnésio, manganês e zinco, além de diluir outros componentes e tornar a dieta menos palatável Geraldo et al.(2006).

As exigências nutricionais de cálcio e fósforo das aves variam em função da linhagem, da taxa de crescimento e da produção de ovos, da relação entre os minerais, o conteúdo de vitamina $\mathrm{D}$, na proporção de fósforo que aparece ligado ao fitato, na temperatura ambiente e, por fim a densidade energética das rações (Underwood, 1983).

Para galinhas poedeiras, a primeira fase do período de postura compreende o entre dia que se registra a maturidade sexual do lote de aves até aproximadamente 45 semanas de idade e, em função disto, o manual de manejo da linhagem Dekalb White recomenda níveis de 3,80 a 3,90\% de cálcio e 0,44 a $0,48 \%$ de $\mathrm{Pd}$, para que as frangas de maturação precoce possam desenvolver completamente os ossos medulares. Ainda de acordo com este manual, o período de produção II (após 45 semanas de idade) se estende até aproximadamente 80 semanas de idade. E, a ingestão diária de cálcio para esta fase, deve variar entre 3,90 a 4,10 gramas por dia, enquanto que para o consumo de Pd seja de 440 a 460 miligramas/dia. No entanto, estas informações ultrapassam os valores sugeridos por Rostagno et al. (2011), que recomendam a exigência nutricional de Ca:Pd disponível para poedeiras leves a proporção de $12: 1$ ou 4,02 gramas de cálcio e 310 miligramas de fósforo.

Em relação à vitamina $\mathrm{D}$, sua presença tornase importante para a absorção de cálcio no intestino e para o controle das concentrações séricas do fosfato. Toda vitamina $\mathrm{D}$ encontra-se presente inativa nas células epiteliais, e após ser metabolizada no fígado e, posteriormente no rim passam para a forma biologicamente ativa.

$\mathrm{O}$ fígado primeiro hidroxila a molécula de vitamina $\mathrm{D}$ na posição $\mathrm{C} \quad 25$, e $\mathrm{o}$ rim subsequentemente hidroxila a molécula $\mathrm{C} 1$ para produzir o composto ativo 1,25 dihidroxicolecalciferol D. A deficiência de cálcio nas dietas estimula a produção do paratormônio (PTH) que, por sua vez, promove o aumento da absorção e mobilização de cálcio pelos ossos através da síntese de vitamina D. A situação ocorre de maneira oposta, quando o animal dispõe de fósforo em excesso, isto é, a hidroxilação ocorre na molécula C 24 ao invés da C 1 pelos rins que leva a formação da forma inativa 24,25 - dihidroxicolecalciferol D. Quando há um decréscimo nas concentrações séricas deste mineral, ocorre a formação da forma ativa 1,25 - dihidroxicolecalciferol D pela hidroxilação da molécula $\mathrm{C} 1$ nos rins. A medida que as aves envelhecem, ocorre maior mobilização de cálcio estrutural para atender as necessidades de formação da casca dos ovos, isto ocorre principalmente, em galinhas poedeiras de alta produção favorecendo a incidência de osteoporose Abe et al (1982) e Newman \& Leeson (1997).

Estudos realizados sobre a capacidade de aves mais velhas em metabolizar a vitamina $D$ têm mostrado que, embora possa haver níveis semelhantes de produção de 1,25 (OH) D entre os rins das galinhas mais jovens e os das aves mais idosas, as matrizes quando são submetidas a dietas com restrição de cálcio, promovem uma 
redução tanto na qualidade da casca dos ovos quanto os parâmetros de resistência óssea segundo Bar e Hurwitz (1984). Ainda neste trabalho os autores afirmam que, a atividade de 25-hidroxilação realizada no fígado de galinhas velhas podem ser afetada não apenas pela idade, mas sim pela diminuição da capacidade do metabolismo em produzir níveis adequados de $1,25(\mathrm{OH}) \mathrm{D}$ necessária para atender às exigências das aves.

\section{Fitato}

A alimentação dos animais monogástricos é basicamente composta de ingredientes de origem vegetal, porém o conteúdo de fitato fosfórico presentes nestas matérias primas usadas nas formulações é bastante variável, afetando diretamente a biodisponibilidade do fósforo.

De acordo com o National Research Council (1994), o milho e o farelo de soja que são os alimentos convencionais usados nas dietas de aves e suínos, possuem percentagens de aproximadamente $0,28 \%$ e $0,65 \%$ de $\mathrm{P}$ total em suas composições respectivamente. Já, o farelo de arroz integral, com ampla disponibilidade no mercado brasileiro, apresenta $1,67 \%$ de $\mathrm{P}$ total $1,67 \%$ segundo Rostagno et al. (2011), entretanto é um ingrediente que possui uma das menores taxas de disponibilidade de $\mathrm{P}$, em função da presença do seu alto teor de fitato.

O fitato é a maior reserva de fósforo da planta. O ácido fítico é formado pela esterificação do álcool cíclico inositol com seis grupos de ácido fosfórico, e o fitato é o duodeca-ânion do ácido fítico, o qual é chamado quimicamente de ácidoinositol- hexafosfórico, pois o mesmo reduz a disponibilidade do fósforo e forma complexos insolúveis com compostos orgânicos presentes nos alimentos, como por exemplo, as proteínas dietéticas associados com elementos como o cálcio, cobre, zinco, magnésio, manganês e ferro presentes nos alimentos. Estes complexos por sua vez, adquirem resistência à digestão enzimática dificultando a utilização destes nutrientes pelas células.

\section{Fontes de fósforo}

Além das fontes inorgânicas de $\mathrm{P}$ encontradas no mercado na forma de fosfatos bicálcico, monocálcico, monoamônios e os de rocha desfluorizada, a Farinhas de carne e ossos, também são utilizadas largamente em dietas para frangos de corte e poedeiras comerciais, atuando geralmente como ingrediente redutor nos custos de formulações. No entanto, a determinação da biodisponibilidade do fósforo dos fosfatos é realizada de forma comparativa, ou seja, utilizase como uma fonte padrão, o fosfato bicálcico, ao qual foi atribuído o coeficiente de disponibilidade de $100 \%$, e por isso, alguns fosfatos apresentam conteúdo de fósforo disponível maior que $100 \%$.

Segundo Fernandes (1996), a variação na disponibilidade do fósforo tanto em ingredientes de origem vegetal, quanto em suplementos comerciais é bastante evidente, pois sendo cada vez mais necessário estudos que tornem $\mathrm{o}$ conhecimento da disponibilidade destas fontes. permitindo formular rações com mais seguranças para os animais e o meio ambiente.

\section{Exigências de fósforo}

As necessidades de fósforo estão sujeitas a muitas variáveis, entre elas estão as contribuições de cálcio e da vitamina D. Todavia, a idade da aves também pode ser considerado um fator que interfere diretamente sobre as exigências nutricionais, pois aves em final de criaçao, por exemplo, podem aumentar o aproveitamento do fósforo complexado ao ácido fítico, em consequiência da plena atividade enzimática do sistema digestivo, segundo Laurentiz et al. (2007).

A alta produção de ovos permite que as exigências de fósforo seja elevada proporcionalmente em relação aos valores encontrados no ovo, sendo de aproximadamente 120 miligramas, de acordo com Underwood (1981). Isto se deve ao aumento do catabolismo de fósforo e as perdas associadas com a produção de ovos. As condições de criação, manejo, instalações, além de temperaturas elevadas também incidem sobre as necessidades de fósforo, promovendo a redução do consumo de ração e declínio no desempenho geral das aves.

Sakomura et al. (1995) não observaram efeitos sobre a produção de ovos, conversão alimentar e peso médio dos ovos com aves alimentadas com diferentes níveis de fósforo, porém a redução do consumo em função do aumento da temperatura ambiente causou perda de peso das aves que consumiram dietas com níveis de até $0,20 \%$ de Pd. Ainda neste trabalho, os autores determinaram que a estimativa de fósforo para estas aves em fase de produção está em torno de $0,34 \%$ e que, estas exigências podem ser reduzidas com avanço da idade. 
As recomendações dos níveis de Pd para poedeiras leves apresentam variações em relação ao longo do seu período produtivo, pois tanto nas pesquisas pubilcadas quanto nos manuais das linhagens, as estimativas variam de 0,15 até $0,50 \%$ Leeson \& Summers (2001); Silva et al., (2008).

Em trabalhos realizados por Van der Klis et al. (1996); Boling et al. (2000) demonstraram que a suplementação de 150 a 200 miligramas, ou seja, 0,15 a $0,20 \%$ de Pd na dieta tem sido suficiente para manter desempenho adequado das aves. No entanto, Silva et al (2008), estudando diferentes razões cálcio:fósforo para poedeiras semi pesadas concluíram que para ser obter um bom desempenho produtivo, o nível de $0,38 \%$ ou 380 miligramas seja recomendável para uma adequada suplementação.

Choi et al. (1979) concluíram que a galinha poedeira mantém um nível de fósforo plasmático proporcional ao conteúdo de fósforo na dieta até certos limites. Porém, os níveis de fósforo plasmático reduzem quando as aves são submetidas a dosagens abaixo dos valores normalmente administrados.

Estudos realizados por Keshavarz (2000) utilizando galinhas poedeiras com 42 a 54 semanas de idade, relata que os níveis entre 0,20 e $0,30 \%$ de Pd não afetaram a produção e as características da qualidade das cascas dos ovos, sugerindo um consumo diário abaixo do nível recomendado pelo NRC (1994) de 250 $\mathrm{mg} /$ ave/dia. Neste mesmo trabalho, com as mesmas aves, sendo na fase de 54 a 66 semanas de idade, o autor afirma um nível ideal de $0,15 \%$ de $\mathrm{P}$ para se obter o melhor índice de gravidade específica dos ovos, no entanto, foi observado uma redução significativa sobre os índices produtivos. Porém, Summers et al. (1995) observaram uma redução na produção de ovos após 32 semanas de idade, usando dietas com $0,20 \%$ de fósforo disponível.

\section{Conclusão}

Considerando que após o pico de produção de ovos as aves demonstram necessidades especiais com relação ao seu aporte nutricional, conclui-se que a exigência de $0,30 \%$ e $0,32 \%$ fósforo disponível seja suficiente para manutenção das características de desempenho e qualidade dos ovos respectivamente.

\section{Referências Bibliográficas}

Ballam, G. C.; Nelson, T. S. \& Kirby, L.K. 1984. Effect of fiber and phytate source and of calcium and phosphorus level on phytate hydrolysis in the chick. Poultry Science, 63, 333-338.

Bar, A. \& Hurtwitz, S. 1984. Eggshell quality, medullary bone ash, intestinal calcium and phosphorus absorption and calcium-binding protein in phosphorus-deficient hens. Poultry Science, 63, 1975-1979.

Barbosa, N.A.A., Sakomura, N.K., Mndonça, M.O., FreitasS, E.R. \& Fernandes, J.B.K. 2008. Qualidade de ovos comerciais provenientes de poedeiras comerciais armazenados sob diferentes tempos e condições de ambientes. ARS Veterinária, 24, 127-133.

Bertechini, A.G. 2006. Nutrição de monogástricos. Lavras: Editora UFLA.

Dolling, S.D., Douglas, M.W., Jihnson, M.L., Wang, X., Pearson, C.M., Kolbeck, K.W \& Zimmerman, R.A. 2000. The effects of dietary available phosphorus levels and phytase on performance of young and older laying hens. Poultry Science, 79, 224-230, 2000.

Borges, F.M.O. 1997. Utilização de enzimas em dietas avícolas. Cadernos Técnicos da Escola de Veterinária da Universidade Federal de Minas Gerais, Belo Horizonte, 20, 5-30

Butolo, J.E. 2002. Qualidade dos Ingredientes na Alimentação Animal. Campinas - SP, Colégio Brasileiro de Nutrição Animal. 432p.

Choi, J.H., Miles, R.D, \& Harms, R.H.. 1979. The response of serum inorganic phosphorus level in laying hens fed low levels of dietary phosphorus. Poultry. Science, 58, 416-418.

CONAB 2013. Proposta de Preços Mínimos Safra 2013/14. Companhia Nacional de Abastecimento, 2. Disponível em: http://www.conab.gov.br/OlalaCMS/uploads/ arquivos/13_11_22_15_41_10_pm_verao_13 14.pdf. Acessado em 07/10/2014.

Conte, A. J. 2002. Efeito da fitase na biodisponibilidade do fósforo do farelo de arroz em frangos de corte, Pesquisa Agropecuária Brasileira, Brasília, 37, 547552.

De Langer, K., Nyachoti, M. \& Bierkett, S. 1999. Manipulation of diets to minimize the 
contribution to environmental pollution. Advances in Pork Production, 10, 173-186.

Dias, R. S. 2006. Estudos do metabolismo do fósforo utilizando modelos matemáticos. Tese (Doutorado - Área de Energia Nuclear na Agricultura) - Universidade de São Paulo, Piracicaba.

Faria, D. E. Junqueira, O. M., Sakomura, N. K. \& Santana, A.E. 2000. Efeito de diferentes níveis de sódio e fósforo sobre o desempenho e qualidade de casca de ovos de poedeiras comerciais. Revista Brasileira de Zootecnia, 29, 458-466.

Fernandes, J. I. M. 1996. Fósforo disponível para frangos de corte em fosfato de uso agrícola. 1996. 171f. Dissertação (Mestrado). Faculdade de Medicina Veterinária e Zootecnia, Universidade de São Paulo, Pirassununga.

Geraldo, A.; Beterchini, A. G.; Brito, J. A. G.; Kato, R. K., \& Fassani, E. J. 2006. Níveis de cálcio e granulometrias do calcário para frangas de reposição no período de 3 a 12 semanas de idade. Revista Brasileira de Zootecnia, 35, 113-118.

Keshavarz, K. 2000. Nonphytate phosphorus requirement of laying hens with and without phytase on a phase feeding program. Poultry Science, 79, 613-798.

Laurentiz, A. C.; Junqueira, O. M.; Filardi, R. S. Casartelli, E. M. \& Costa, R. 2007. Efeito da adição da enzima fitase em rações para frangos de corte com redução dos níveis de fósforo nas diferentes fases de criação. Ciência Animal Brasileira, 8, 207-216.

Lima I. L. 1995. Disponibilidade de fósforo e de flúor de alguns alimentos e exigência nutricional de fósforo para frangos de corte. Viçosa, MG: Universidade Federal de Viçosa, 1995. 121p. Dissertação (Doutorado em Zootecnia) - Universidade Federal de Viçosa.

NRC. 1994. Nutrient requirements of poultry. 9.ed. Washington (DC): National Academy Press, $155 \mathrm{p}$.

Newman, S. \& Leeson, S. 1997. Skeletal integrity in layers at the completion of egg production. World's Poultry Science Journal, 53, 265-277.

Rostagno, H. S. 2011. Tabela Brasileira de Aves e Suínos (Composição de alimentos e exigências nutricionais). Impr. Universidade Federal de Viçosa, 184p.

União Brasileira de Avicultura - UBABEF. Relatório Anual. Disponível em: http://www.abef.com.br/ubabef/publicacoes $\mathrm{r}$ elatoriosanuais.php.15Fev.2013. Acessado em: 07/10/2014

Sakomura, N. K. 1995. Exigência nutricional de fósforo para galinhas poedeiras. Revista Brasileira de Zootecnia, 24, 936-951.

Silva, J. H. V.; Araújo, J. A.; Goulart, C. C.; Costa, G. P.; Sakomura, N. K \& Martins, T. D. D. 2008. Relação cálcio:fósforo disponível e níveis de fitase para poedeiras semipesadas no primeiro e segundo ciclos de postura. Revista Brasileira de Zootecnia, 37, 21662172.

Silversides, F. G.; Scott, T. A. \& Korver, D. R. A 2006. Study on the interaction of xylanase and phytase enzymes in wheat based diets fed to commercial white and brown egg laying hens. Poultry Science, 85, 297-305.

Singh, P.K. 2008. Significance of phytic acid and supplemental phytase in chicken nutrition: A review. World's Poultry Science Journal, 64, 553-580.

Summers, J. D. 1995. Reduced dietary phosphorus levels for layers. Poultry Science, 74, 1977-1983.

Umderwood, E. J. \& Suttle, N. F. 1981. The mineral nutrition of livestock $2^{\mathrm{a}}$ ed. London; Commonwealth Agricultural Bureal, 174p.

Van Der Klis, J. D.; Versteegh, H. A. J \& Simons, P. C. M. 1996. Nathuphos symposium phosphorus and calcium management in layers. Atlanta, USA, BASF, 1997, 71-82.

Wu, G.; Liu, A. \& Bryant, M. M. 2006. Comparison of natuphos and phyzyme as phytase sources for commercial layers fed corn-soy diet. Poultry Science, 85, 64-79.

\section{Recebido em Novembro 18, 2014}

Aceito em Maio 29, 2015

License information: This is an open-access article distributed under the terms of the Creative Commons Attribution License, which permits unrestricted use, distribution, and reproduction in any medium, provided the original work is properly cited. 